\title{
Construction of English Learning Portfolio System
}

\author{
Chunhua Cui \\ College of Foreign Languages, Bohai University, Jinzhou, 121013, China \\ 13841603520@163.com
}

Keywords: learning portfolio; system development technology; system architecture design; system module design; database design; system process design

\begin{abstract}
Nowadays, English has become an important subject of entrance examination for students, English directly decides the success or failure of the entrance examination. In order to facilitate the students for a long period of time to save English learning materials, notes, test results and other relevant information, timely understanding of the current situation of English learning and their own English level, do a summary to the present stage of English learning, a planning for English learning in the future. This paper adopts the ASP technology to build the English learning portfolio system, which provides the reference for the follow-up of software development. Mainly from five aspects of the ASP technology, the system architecture design, system module design, database design and system process design to build the system. Students through the system review previous learning materials, notes and test scores to reflect and evaluate their previous English learning situation, gradually forms a serious attitude of learning and an ability of independent learning. The research content of this article has important reference to improve the students' English level and the enthusiasm of English study..
\end{abstract}

\section{Introduction}

Electronic learning portfolio is defined that in the information technology environment, the learners use information technology to perform and display that an aggregation of learning objectives, learning activities, learning outcomes and learning performance, learning pay, academic progress, and the study of reflecting on the learning process and learning result in the learning process [1]. It is mainly used to examine the achievements of students obtain through learning knowledge, the students can independently obtain the information of electronic learning portfolio such as learning outcomes, learning performance, according to the selected information to judge their own learning quality and progress.

Language is an important tool for humans to communicate with others, also the basic conditions for humans to participate in social activities. In the modern life and the background of economic increasing globalization, English has become the most widely used international language in the field of human life , many countries and regions will take English as an important tool to interact with each other [2]. For students, English is a compulsory course for the basic education stage, which is also one of the major languages in foreign language courses [3]. In the present stage, because all the relevant information of students' English learning materials, exam papers and test scores are not preserved for a long time, it is not possible that students want to know at any time about the quality of English learning and their own English level at the present stage, students just blindly learn English and can not make a judgment for their own English learning situation , which is not conducive to the students' English learning. In order to solve this problem, this paper proposes to establish electronic learning portfolio, using ASP technology to build English learning portfolio system. The system can preserve related information of the students' English learning materials, examination papers, test scores, which realizes the information management. Students can at any time obtain the wanted information, according to the selected information judge the quality of their own learning and progress. The system can help students to reflect and judge their previous English learning situation, gradually form a serious attitude of learning and the ability of independent learning, which has important significance to improve the students' English level and the enthusiasm of English learning. 


\section{ASP Technology}

ASP technology introduction: ASP technology is a kind of server scripting environment, it can be combined with HTML page, script commands and ActiveX components to create interactive Web pages and powerful applications based on Web [4]. ASP replaces the traditional CGI script, can interact with databases and other applications, which is one of simple programming tools of Microsoft research. ASP is mainly used to create dynamic WEB applications, web page file format is .asp, the web page includes images, script commands and plain text content, more common in the dynamic website, which is currently one of the most popular dynamic server page. Strong compatibility, which can achieve perfect compatibilities with many browsers, ensure the normal operation of the system in most browsers, improve the extensiveness of the application of the system. Secondly, through ASP technology create the system dynamic Webpage, which can realize real-time interactions between users and the system database, get the information what the users want, enhance the interactivity of the system.

ASP mechanism: The ASP script is stored in the Web service in the form of .asp file. When the browser through the HTTP sends the service request command to the Web service, Web service calls the corresponding ASP file; ASP executable file asp.dll is responsible for reading the source code of the ASP page from the server, which is then parsed, find out the corresponding ASP script of the server and sent to the corresponding script engine to carry out; execution result will be combined with static HTML in the ASP Webpage and template text files together to generate a complete web page. This web page is a static web page, the server will send the web page to the client browser through HTTP, the operation mechanism is shown in Fig. 1 [5].

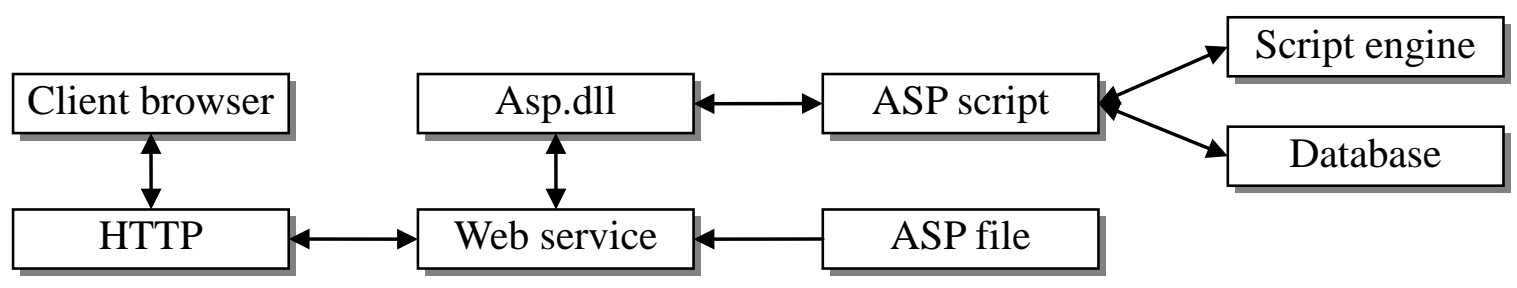

Fig. 1. ASP operation mechanism

ASP adopts ActiveX technology which is developed by Microsoft, it is an important technical means of software research and development of Microsoft. It uses a technology of procedure calls and object encapsulation to reduce the complexity of programming, strengthen the relationship between the structure of the program. Some common components are encapsulated in ASP, many companies also have developed their own utility components. Software developers install these components on the server, through access to these components, who can quickly and easily build Web applications.

ASP runs on a Web server, drastically strengthens the compatible between programming language which ASP uses and most browsers. ASP through the Web server returns the standard HTML page, the browser will parse it and then display to the user. Users view the page source files, what they see is just the ASP generated HTML page code, rather than the system itself written ASP program code, which effectively prevents leakage and loss of data, avoids the system source code to be copied.

\section{System Architecture Design}

In this paper, the design of English learning portfolio system architecture uses B/S architecture. B/S architecture is a kind of three layer system structure, it is based on C/S structure, which is a kind of improvement and upgrade architecture of C/S structure. C/S structure is a kind of two layer system structure based on distributed processing, through the rational allocation of tasks to the client and the server, which reduces the communication overhead of the system, it can make full use of the advantages of both ends of the hardware environment to reduce all kinds of bottleneck problem of computer system [6]. If the system uses the C/S architecture, the existence of the following several major problems: (1) the users before using the system have to install special client software, after 
the version of the system is upgraded, but also have to re-install the software system, which is more complicated, the cost of upgrading the system is high. (2) The system is only applicable to the specific operating system, cannot be compatible with most operating systems, the adaptability of the system is poorer, which leads system developers need according to the different operating systems to develop different versions, low efficiency, high cost, high investment cost. (3) The system needs high maintenance costs. If the system uses the B/S architecture, the server provides a Web service, the user can access the system through the browser to interact with the system database, and then completes the required operations. Users do not need to install a specific client software, no need to make daily maintenance of the client software, greatly reduces the amount of user data processing, the load borne by the user, the workload and cost of system maintenance and upgrade consumption [7]. Based on the comparison of the above two kinds of architecture, this paper uses B/S architecture to design English learning portfolio system architecture.

System architecture based on this paper designs adopts B/S architecture, system architecture is divided into three layers, from top to bottom as follows: the client, the application layer, logic business layer and data access layer. Among them, the client includes two customers, students and administrators both can access the system through the browser; The application layer is the browser, all operations of users are executed on the system Webpage, the browser is responsible for sending the parsed user service request command to the Web server, presenting the executed results to the user at the same time; the logic business layer is the Web server, which is responsible for executing the instruction and obtaining the corresponding data in the database, and sending the executed results to the browser. The data access layer is the system database, which is responsible for implementing data request instructions which Web server sends, and will returning the executed results back to the Web serve. System architecture is shown in Fig. 2.

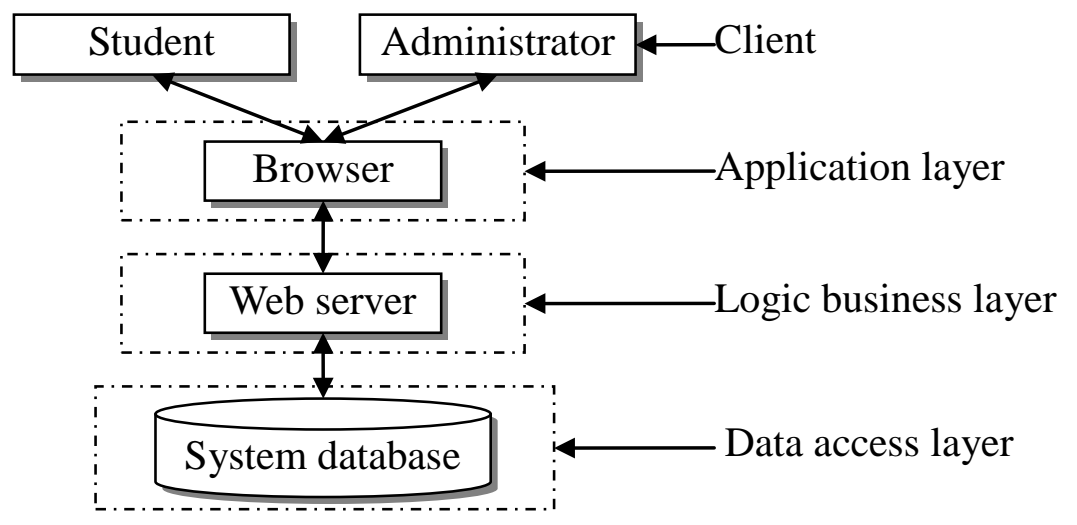

Fig. 2. System architecture

\section{System Module Design}

In this paper, according to the actual demand, the system module is divided into two big modules of students and administrators. The functions of the students module design include account information, learning materials, test papers, reflection diaries, study notes, scores archives, reviews archives; Among them, account information says that students can register an account which is not existed in the system, modify the account password; Learning materials say that students can view, modify, delete, or add their own previous learning materials to the system database; test papers say students can view, modify, delete, or add the content of their own previous test papers to the system database; Reflection diary says that students can view, modify, delete or add their own insights and experiences in the previous learning process to the system database; Learning notes say that students can view, modify, delete, or add recorded lecture notes during the period of school and their own summary notes when they learn after class; scores archives say that students can view, modify, deleted or add test scores of each semester during the period of school to the system database; reviews archives say students can view, modify, delete, or add teacher comments of each semester during the period of school to the system database. 
The functions of the administrators module design include account management, rights management, system maintenance; among them, account management says that administrator can add, view account information; rights management says that administrators can view, modify the permissions users access to the system; system maintenance says that administrator should be regularly to repair the loopholes in the system, prevent leakage and loss of data; improve the function of the system according to the needs of users. In this paper, the design of system module function is shown in Fig. 3.

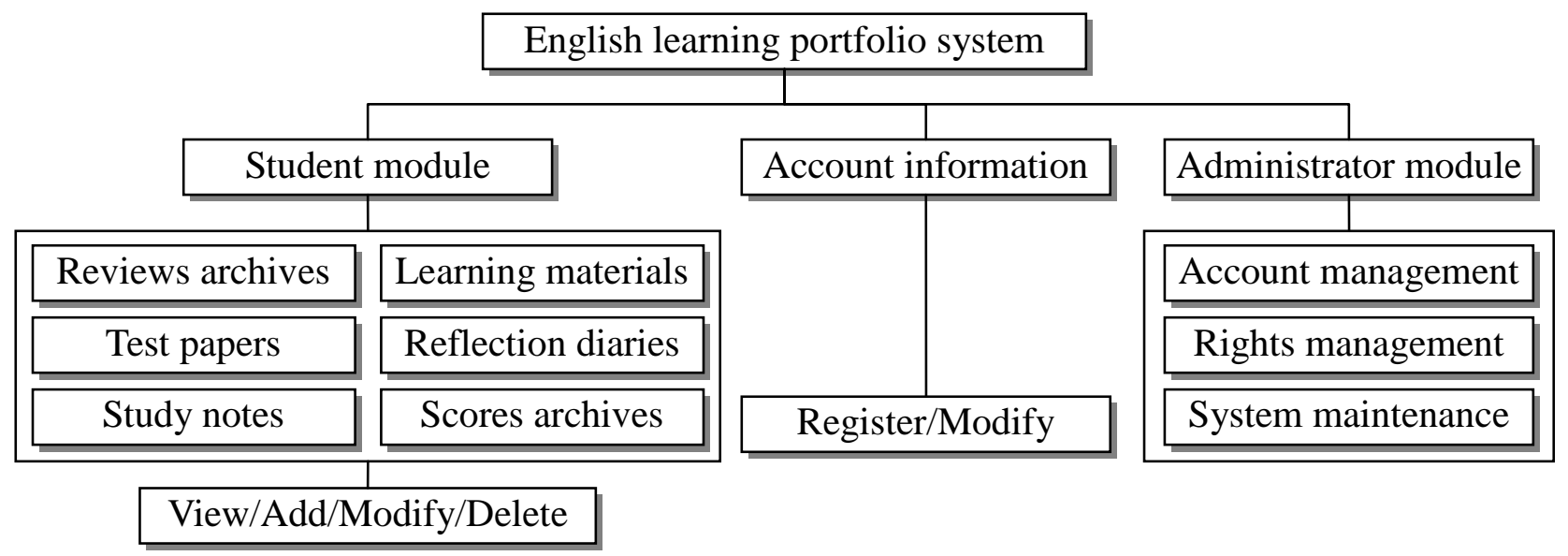

Fig. 3. System module function

\section{Database Design}

Database connection: Fully consider the system need to store large amounts of data, frequent data interactions between user, in this paper, the system database adopts the Oracle database, Oracle database system is the current mainstream database in the world, which is a relational database with the characteristics of a set of large business volume, large storage capacity, extremely flexible [8]. There are three kinds of common methods which are used to connect ASP with oracle database. First, the use of ODBC, the stability of the connection is bad; the second, the use of ADO which is developed by Microsoft, it is a kind of application program interface, specifically for the implementation of accessing data in the database; the third, the use of oracle database own asp driver, high stability of the connection , fast speed. This paper adopts the third kind of connection method, the main code as follows.

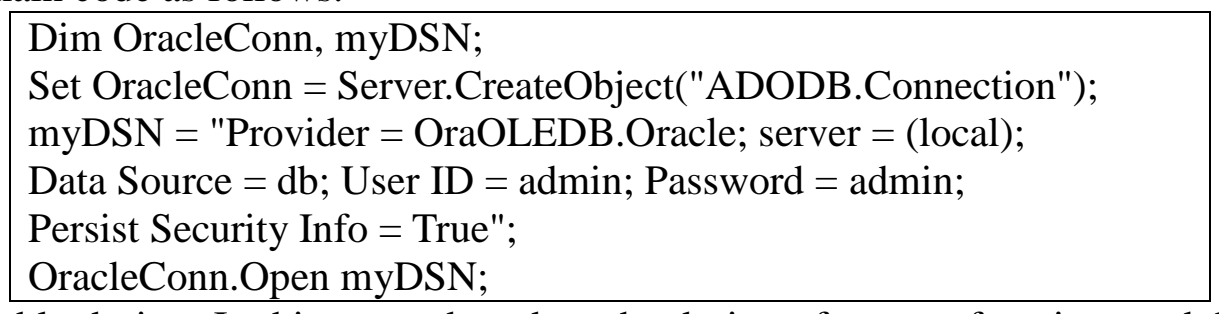

Database table design: In this paper, based on the design of system function module, the system database mainly includes two categories that the students module information table and the administrators module information table. Among them, the student module information table includes account information, learning materials, test papers, reflection diaries, study notes, scores archives, reviews archives; the administrator module information table includes account management, rights management. Taking the students' scores archives information table as an example to design the composition and structure of the data, the specific table structure is shown in Table 1. 
Table 1. Scores archives information table

\begin{tabular}{c|c|c|c:l}
\hline $\begin{array}{c}\text { Serial } \\
\text { Number }\end{array}$ & $\begin{array}{c}\text { Fields } \\
\text { Name }\end{array}$ & $\begin{array}{c}\text { Fields } \\
\text { Type }\end{array}$ & $\begin{array}{c}\text { Fields } \\
\text { Width }\end{array}$ & Illustration \\
\hline 1 & ID & Int & 5 & Automatic number \\
\hline 2 & Semester & Int & 10 & Test Semester \\
\hline 3 & Entrance & Number & 5 & Students' entrance English scores \\
\hdashline 4 & Middle & Number & 5 & Students' middle English scores \\
\hline 5 & Final & Number & 5 & Students' final English scores \\
\hline 6 & School & Varchar & 40 & School \\
\hline 7 & Class & Varchar & 10 & Class \\
\hline 8 & Ranking & Int & 5 & Class rank of English scores \\
\hline
\end{tabular}

\section{System Process Design}

System processes can be indicated of system flow chart. System flow chart is the traditional tools of drawing system physical model, which expresses the flow of the system components, rather than the control process of information processing [9]. English learning portfolio system is designed with "student" and "administrator" two kinds of users, setting "administrator" user access to the system as an example, the design of overall process the user accesses to the system, as shown in Fig. 4.

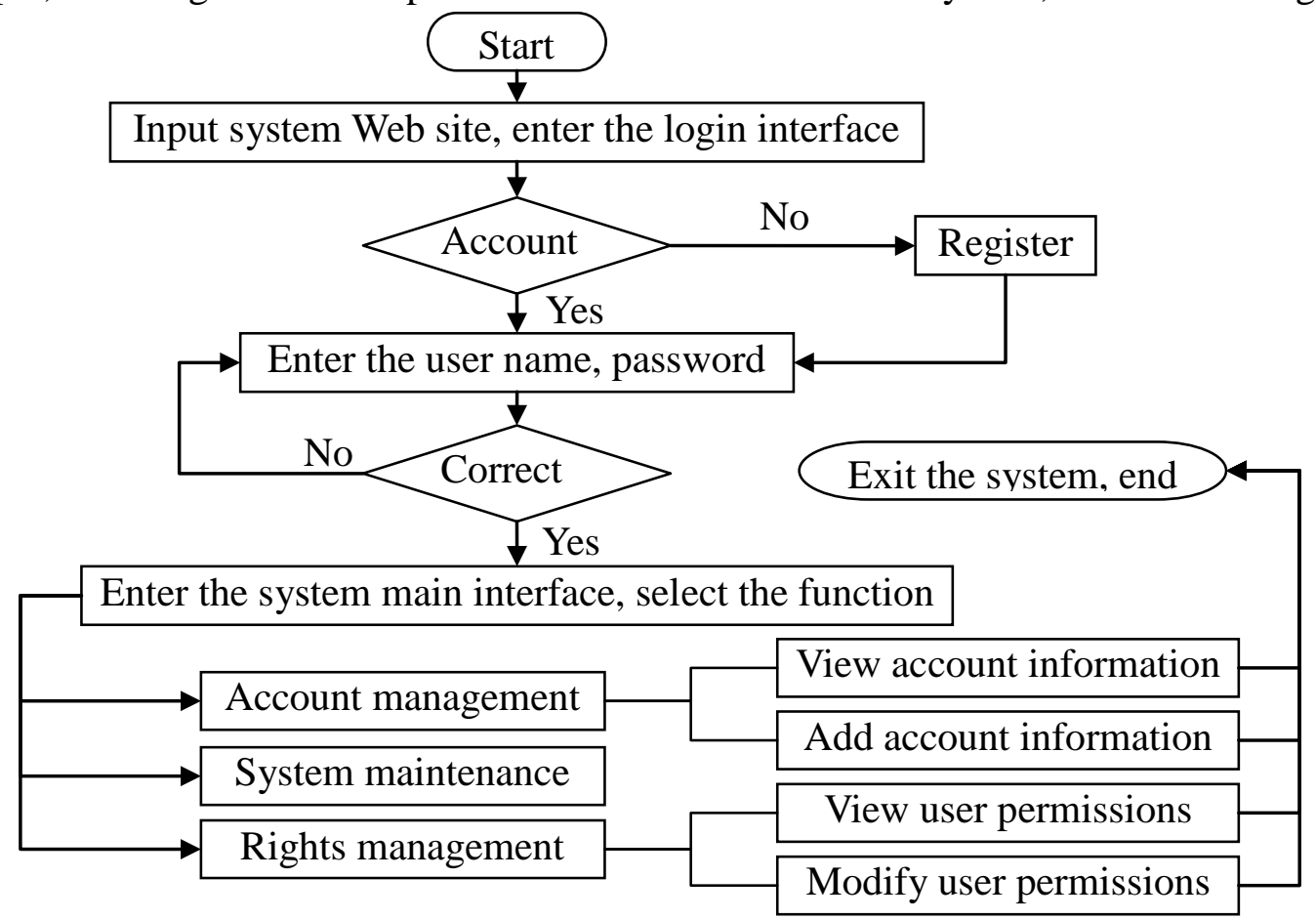

Fig. 4. Student user flow chart

System process design description: the user logins browser to input system Web site and then enters system login interface. For the first time when the user logins the system, the system prompts the user whether has an account; If any, the system prompts the user to enter account information; If not, the system prompts the user to register an account, after the success of the registration, the system prompts the user to login system again, at this point, the user inputs the user name and password again. If input correctly, the user enters system main interface and can choose three functions: account management, rights management and system maintenance; otherwise, the user needs to enter again, until the user enters the correct user name and password. Select account management functions, the user can view or add account information; Select rights management functions, the user can view or modify user permissions. When the user required operations are completed, the 
user can choose to exit the system.

\section{Conclusion}

English as an important subject of entrance exam has received students' more and more attention, students take a large part of time to learn English. At present, most of the students just blindly learn English, they cannot make a judgment for their own English learning situation. Because all the relevant information of students' English learning materials, exam papers and test scores are not preserved for a long time, it is not possible that students want to know at any time about the quality of English learning and their own English level at the present stage, which is not conducive to the students' English learning. Network technology is a new technology developed in the mid-nineties, it turns the Internet distributed resources into an organic whole to achieve comprehensive sharing and organic collaboration of the resources, which enables people to transparently use the overall capacity of resources and obtain information according to the demands [10]. Combined with the characteristics of the network technology, this paper adopts ASP technology to construct English learning portfolio system. The system can preserve related information of the students' English learning materials, test papers, test scores, which realizes the information management. Students can at any time obtain the wanted information, according to the selected information judge the quality of their own learning and progress, scientifically and effectively learn English. The system can help students to reflect and judge their previous English learning situation, gradually form a serious attitude of learning and the ability of independent learning, which has important significance to improve the students' English level and the enthusiasm of English learning.

\section{References}

[1] J. Zhang, "Introduction of The Use of Electronic Learning Portfolio (e-Portfolio) Under The Web in College English Teaching," Modern Enterprise Education, vol. 28, no. 10, pp. 204, 2011.

[2] G. Z. Jia, "A Comparative Study of Value Orientation of Senior High School English Textbooks Under New Curriculum Standards," Shanxi: Master Degree Thesis of Shanxi Normal University, 2014.

[3] S. P. Tan, "Excitation Strategy Research of The Initiative of English Learning of Rural Middle School Students," Guangxi: Master Degree Thesis of Guangxi Normal University, 2014.

[4] H. Y. Bao, "Research and Implementation of E-Government Portal Website Based on ASP Technology," Journal of Jinzhong University, vol. 28, no. 3, pp. 67-70, 2011.

[5] H. Zhou, "Design of Class Electronic Portfolio System," Chengdu: Master Degree Thesis of University of Electronic Science and Technology, 2009.

[6] B. Wang, Q. Li, "Design and Implementation of Employee Information Management System Based on C/S Mode," Software Guide, vol. 11, no. 8, pp. 111-112, 2012.

[7] L. L. Zheng, L. H. Song, R. Guo, J. C. Zhang, "Research on Security Testing to B/S Structure Software," Computer Technology and Development, vol. 22, no. 1, pp. 221-224, 2012.

[8] C. Liu, M. A. Zhang, "Backup and Recovery Technology Based on Oracle Database," Software, vol. 35, no. 3, pp. 125-129, 2014.

[9] Baidu Baike, "Flow Chart," http://baike.baidu.com/view/1140574.htm, 2016-1-29.

[10] Baidu, "Network Technique," http://baike.baidu.com/view/25363.htm, 2016-1-29. 